\title{
Conservação e vigor de sementes de pau-de-balsa (Ochroma pyramidale).
}

\author{
Antonio Moçambite PINTOํ, Mario Takao INOUE ${ }^{2}$, Antonio Carlos NOGUEIRA²
}

\begin{abstract}
RESUMO
Ochroma pyramidale, Bombacaceae, conhecida popularmente como pau-de-balsa, é utilizada para construção de jangadas, balsas, salva-vidas, bóias, brinquedos e na fabricação de papel e celulose. O objetivo deste estudo foi definir um método de acondicionamento de sementes de $O$. pyramidale, visando a conservação da viabilidade e vigor destas para sua utilização e comercialização em épocas de baixa produção. Sementes de $O$. pyramidale foram embaladas em sacos de papel tipo kraft e sacos de plástico $(0,10 \mathrm{~mm})$ e armazenadas em ambiente de laboratório $\left(22^{\circ} \mathrm{C}\right.$ e $65 \%$ U.R.), câmara úmida $\left(5^{\circ} \mathrm{C}\right.$ e $86 \%$ U.R.) e câmara seca $\left(15^{\circ} \mathrm{C}\right.$ e $40 \%$ U.R.). A percentagem de germinação, teor de água e vigor das sementes foram avaliados no início e após períodos de armazenamento. Todos os tratamentos testados foram favoráveis para manutenção do vigor das sementes por 120 dias de armazenamento. As melhores condições de armazenamento para manter a viabilidade por até 400 dias foram: sacos de papel (76,5\% de germinação) e sacos plásticos (65,5\% de germinação) em câmara seca, e sacos plásticos em condições de laboratório (63,5\% de germinação).
\end{abstract}

\section{PALAVRAS-CHAVE}

Ochroma pyramidale, germinação, viabilidade, embalagem, umidade, condições de armazenamento, temperatura.

\section{Conservation and vigour of balsawood seeds (Ochroma pyramidale).}

\begin{abstract}
Balsawood (Ochroma pyramidale, Bombacaceae) is used for construction of rafts, floats, life-savers, buoys, toys and for paper and cellulose production. The objective of this study was to determine a seed storage method for $\mathrm{O}$. pyramidale to conserve seed viability and vigour for use and commercialization during seasonal shortages. Seeds were put in paper (Kraft) and plastic bags $(0.10 \mathrm{~mm})$, and stored in three environmental conditions: laboratory $\left(22^{\circ} \mathrm{C}\right.$ and $65 \%$ relative bumidity), bumid chamber $\left(5^{\circ} \mathrm{C}\right.$ and $\left.86 \% \mathrm{RH}\right)$ and dry chamber $\left(15^{\circ} \mathrm{C}\right.$ and $\left.40 \% \mathrm{RH}\right)$. Germination percentage, moisture content and vigour of seeds were evaluated at the beginning of the experiment and after the storage periods. All treatments maintained seed vigour for 120 days of storage. The best storage conditions to maintain seed viability for a 400-day period were: 1) paper bags in the dry chamber (76.5\% germination), 2) plastic bags in the dry chamber (65.5\% germination) and 3) in laboratory conditions (63.5\% germination).
\end{abstract}

\section{KEY WORDS}

Ochroma pyramidale, seed germination, storage conditions, storage packaging, humidity, viability, temperature.

\section{INTRODUÇÃO}

O reflorestamento de grandes áreas torna-se cada dia mais necessário, devido a baixa reposição, alta demanda por produtos e subprodutos, e da extinção de grandes populações de espécies florestais. O pau-de-balsa (Ochroma pyramidale (Cav. ex Lam.) Urban., Bombacaceae) possui importância econômica e social, e é utilizada em plantios mistos destinados à recomposição de áreas degradadas de preservação permanente, graças ao seu rápido crescimento e tolerância à luminosidade direta (Lorenzi, 1992). Sua madeira é de baixa densidade, mas de grande resistência à tensões. É macia e fácil de trabalhar. Pelas suas características, é ideal para a construção de jangadas, balsas, salva-vidas, bóias e brinquedos (Loureiro et al., 1979; Lorenzi, 1992). É igualmente apropriada para a fabricação de papel e celulose; suas fibras são bastante longas e produzem um tipo de celulose de alta qualidade com um grau de rendimento entre 45 a $50 \%$. A celulose crua é, além disso, muito fácil de branquear (Lamprecht, 1990).

Em função da carência de informações silviculturais, concentraram-se as pesquisas nas sementes, tendo em vista

${ }^{1}$ Instituto Nacional de Pesquisas da Amazônia - INPA, CPST, Caixa Postal 478, 69011-970 - Manaus-AM.

${ }^{2}$ Universidade Federal do Paraná - UFPR, Rua Bom Jesus 650, Juvevê, 80035-010 - Curitiba-PR. 


\section{ACTA \\ AMAZONICA}

CONSERVAÇÃO E VIGOR DE SEMENTES

DE PAU-DE-BALSA (OCHROMA PYRAMIDALE) ser o principal meio de propagação desta espécie. Lorenzi (1992) relatou que a viabilidade de sementes de $O$. pyramidale durante o armazenamento é superior a cinco meses, porém não definiu um período exato. Para que se defina melhor o período de armazenamento é necessário tomar alguns cuidados quanto ao teor de água nas sementes. Neste contexto, Roberts (1973) e Bewley \& Black (1985) classificaram as sementes como recalcitrante e ortodoxa, de acordo com sua facilidade de armazenamento e o teor de água. Sementes recalcitrantes são freqüentemente grandes, com taxas metabólicas e respiração maiores; elas não podem sobreviver ao dessecamento e devem manter um teor de água relativamente alto durante o armazenamento para manter a viabilidade e vigor. A viabilidade dessas sementes é muito curta, sendo capaz de sobreviver somente em condições especiais de armazenamento. Sementes ortodoxas são descritas como relativamente pequenas, com taxas metabólicas e respiração menores, as quais podem ser armazenadas com baixa temperatura e teor de água por longo período de tempo. De acordo com Villiers (1978) o teor de água pode ser próximo a 5\%. De acordo com esta classificação e pelo que verificou-se durante o experimento, pode-se afirmar que a espécie em estudo se encaixa no grupo das ortodoxas.

$\mathrm{Na}$ Amazônia, as pesquisas sobre tecnologia de sementes de espécies florestais nativas são insuficientes, principalmente no que se refere às condições de armazenamento para manter a viabilidade por um período prolongado. Isto implica na necessidade de utilização das sementes imediatamente após a colheita, visto que muitas espécies apresentam características recalcitrantes e estas dificuldades impedem o suprimento de sementes para semeadura em época apropriada (Varela \& Barbosa, 1986/87). Além disso, segundo esses autores, existem problemas resultantes da irregularidade de produção de sementes, da diversidade de espécies por área, baixa freqüência por área e dificuldade de acesso às árvores matrizes, as quais ocasionam, frequentemente, a falta de sementes. Este conjunto de dificuldades limita o melhor aproveitamento dessas espécies em programas silviculturais.

Este trabalho teve por objetivo definir um método adequado de armazenamento e acondicionamento de sementes de $O$. pyramidale, visando a conservação da viabilidade e vigor das sementes para possibilitar a utilização e comercialização em épocas de baixa produção.

\section{MATERIAL E MÉTODOS}

O estudo foi realizado no Laboratório de Tecnologia de Sementes, do Departamento de Silvicultura e Manejo, da Universidade Federal do Paraná (UFPR), Curitiba, PR, utilizando sementes colhidas em Benjamin Constant, no dia 12 de novembro de 1995 , de 10 árvores pré-selecionadas de uma mesma população. Estas árvores fazem parte da floresta tropical úmida de terra firme na margem direita da Rodovia Pedro Teixeira, que liga os municípios de Benjamim Constant e Atalaia do Norte, Estado do Amazonas.

Após a colheita dos frutos, foram acondicionados em sacos plásticos por um mês à temperatura de $27^{\circ} \mathrm{C} \pm 2^{\circ} \mathrm{C}$ até a ocasião dos testes em Curitiba, PR, não sendo possível a determinação do teor de água nesta oportunidade, devido a ausência de equipamento apropriado

em Benjamin Constant. No Paraná utilizou-se para o armazenamento as câmaras pertencentes ao Laboratório de Tecnologia de Sementes, da Empresa Brasileira de Pesquisas Agropecuárias (EMBRAPA-CNPF), em Colombo, PR; as sementes foram acondicionadas por ocasião do transporte em caixa de isopor ermeticamente fechada.

Para os testes de rotina (pureza, número de sementes por quilo, peso de mil sementes e teores de água), foram usadas sementes limpas e homogenizadas (Brasil, 1992), sendo que a operação de limpeza e homogenização do lote foi mecânica. Para determinação da germinação e do teor de água, retirou-se do lote uma amostra de 200 sementes para germinação, as quais foram colocadas em germinador tipo Jacobsen, com temperatura constante de $30^{\circ} \mathrm{C}$, usando-se como substrato papel filtro (Netto, 1994). A outra parte foi utilizada para determinação do teor de água pelo método de secagem em estufa a $105 \pm 3^{\circ} \mathrm{C}$ por 24 horas (Brasil, 1992).

As sementes restantes do lote, segundo classificação de Toleto \& Marcos Filho (1977), foram embaladas em dois tipos de recipientes, em sacos de papel tipo kraft e sacos de plástico $(0,10 \mathrm{~mm})$, e armazenadas em ambiente de laboratório $\left(22^{\circ} \mathrm{C}\right.$ e $65 \%$ UR), camara úmida $\left(5^{\circ} \mathrm{C}\right.$ e $86 \%$ UR) e câmara seca $\left(15^{\circ} \mathrm{C}\right.$ e $40 \%$ UR).

A germinação, o vigor (Brasil, 1992) e o teor de água das sementes foram avaliadas no início e aos 120, 240 e 400 dias após o armazenamento. Para superar a dormência das sementes antes da realização dos testes de germinação, aplicou-se o tratamento de imersão das sementes em água fervente por 4 minutos (Netto, 1994).

Para determinação do teor de água das sementes provenientes das diferentes condições de armazenamento (câmara úmida, câmara seca e ambiente de laboratório), foram utilizadas duas repetições com cinco gramas de sementes cada, as quais foram acondicionadas em cápsulas metálicas de $6,0 \mathrm{~cm}$ de tamanho e submetidas a secagem em estufa a $105^{\circ} \mathrm{C} \pm 3^{\circ} \mathrm{C}$ por 24 horas e, em seguida, postas para resfriar antes da pesagem em dessecador.

Os testes de germinação das sementes foram conduzidos em sala de germinação com a U.R. de aproximadamente de $65 \%$ e temperatura de $22^{\circ} \mathrm{C}$, utilizando-se germinador tipo Jacobsen. Foram consideradas sementes germinadas aquelas que emitiram radícula com 1-2 mm e plântulas normais, com os dois contilédones (Brasil, 1992). Efetuou-se a contagem diária do número de sementes germinadas durante um período de 24 dias após a semeadura até a estabilização do processo.

Para avaliar o efeito do armazenamento, utilizou-se um delineamento experimental inteiramente casualizado, em fatorial $\mathrm{P}^{4} \mathrm{X} \mathrm{A}^{3} \mathrm{X} \mathrm{E}^{2}$, cujos tratamentos foram: quatro períodos de armazenamento $\left(\mathrm{P}^{4}\right)$ - 0, 120, 240 e 400 dias; três condições de armazenamento $\left(\mathrm{A}^{3}\right)$ - ambiente de laboratório $\left(22^{\circ} \mathrm{C}\right.$ e $65 \%$ UR), câmara seca $\left(15^{\circ} \mathrm{C}\right.$ e $40 \%$ UR) e câmara úmida $\left(5^{\circ} \mathrm{C}\right.$ e $86 \%$ $\mathrm{UR})$; com dois tipos de embalagens $\left(\mathrm{E}^{2}\right)$ - saco plástico $(0,10$ 


\section{ACTA AMAZONICA}

$\mathrm{mm}$ ) e saco de papel (tipo kraft). Usou-se oito repetições de 25 sementes para cada tratamento, e as médias foram comparadas pelo teste de Tukey ao nível de 5\% de probabilidade.

\section{RESULTADOS E DISCUSSÃO}

\section{Características físicas}

Os testes físicos mostraram os seguintes valores médios para as sementes de pau de balsa:

1) tamanho médio de frutos $=25 \mathrm{~cm}$ de comprimento por $4 \mathrm{~cm}$ de espessura;

2) número médio de sementes por fruto $=1.195$ sementes;

3) tamanho médio de sementes $=3,1 \mathrm{~mm}$ de comprimento por $1,7 \mathrm{~mm}$ de espessura;

4) peso médio de sementes por fruto $=8,1$ gramas;

5) número de sementes por quilo $=158.428$ sementes;

6) peso de mil sementes $=6,3$ gramas;

7) teste de pureza $=99,96 \%$;

8) teor de água inicial $=6,62 \%$;

Pelos resultados deste estudo, esta espécie apresenta características de sementes ortodoxa. Roberts (1973) e Bewley \& Black (1985) descrevem sementes ortodoxas como aquelas relativamente pequenas, com taxas metabólicas e respiração menores, as quais podem ser armazenadas com baixa temperatura e teor de água por longo período de tempo, além de poder sofrer desidratação após a maturação, sem perder sua viabilidade.

9) percentagem de germinação inicial das sementes submetidas a teste de quebra de dormência $=75 \%$. Netto (1994) encontrou percentagem igual quando o tratamento foi a imersão das sementes em água fervente por quatro minutos. Entretanto, dos tratamentos pré-germinativos estudados por Varela \& Ferraz (1991), a escarificação manual seguida por imersão em água durante 6 horas acelerou a velocidade de germinação das sementes e foi o mais eficiente, com $89 \%$.

Nas câmaras úmida e seca (Figura 1) as sementes embaladas em sacos de papel germinaram melhores que a testemunha. Por tratar de sementes com dormência tegumentar, esse resultado pode ter como causa o enfraquecimento do tegumento no decorrer do armazenamento, resultando no aumento do poder germinativo no final do experimento. Resultados similares foram verificados por Zanon $\&$ Carpanezzi (1993): 30 dias após o início do armazenamento de sementes de Grevillea robusta (Cunn. ex R. Br.), espécie do grupo das ortodoxas (Jones, 1967), o poder germinativo aumentou em todos os tratamentos, com exceção do ambiente de laboratório em sacos plástico.

Nas condições das câmaras úmida e seca (Figura 2), o teor de água das sementes obtidas nos períodos de 120, 240 e 400 dias foi superior em relação ao período inicial, quando as sementes foram acondicionadas em sacos de papel. A este respeito, observou-se que nas duas condiçóes de armazenamento, os graus de umidade variaram, sugerindo a busca do equilíbrio higroscópico. Resultados similares foram verificados por Figliolia (1988) ao estudar sementes de copaíba (Copaifera langsdorffii Desf.), espécie do grupo das ortodoxas (Eira et al., 1992), onde conservaram-se melhor quando armazenadas com $7,8 \%$ de umidade nos ambientes frio e seco; as de ipê amarelo anão (Tabebuia chrysotricha (Mart. Ex Dc) Standl., espécie também do grupo das ortodoxas (Carvalho et al., 1976), conservaram-se melhor armazenadas com 8,5\% de umidade.

Verificou-se que os acréscimos de teores de água reduziram a germinação das sementes em condições de ambiente de laboratório (Figuras 1 e 2). No entanto, esses acréscimos não influenciaram na germinação das sementes

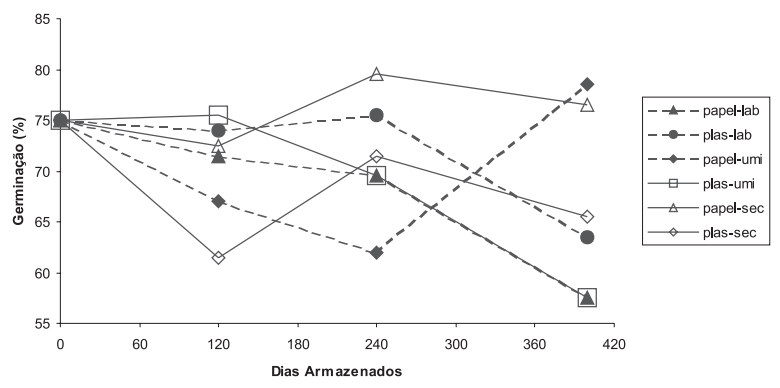

Figura 1 - Percentagens de germinação de sementes de Ochroma pyramidale no início e após 120, 240 e 400 dias de armazenamento em três ambientes e dois tipos de embalagens.

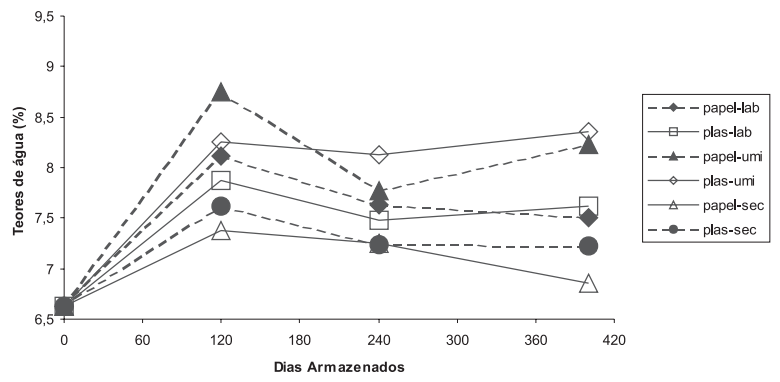

Figura 2 - Percentagens dos teores de água de sementes de Ochroma pyramidale no início e após 120, 240 e 400 dias de armazenamento em três ambientes e dois tipos de embalagens.

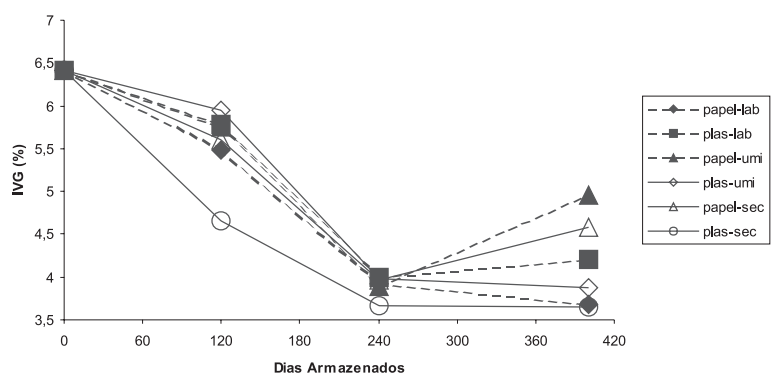

Figura 3 - Médias dos índices de velocidade de germinação (IVG) de sementes de Ochroma pyramidale no início e após 120, 240 e 400 dias de armazenamento em três ambientes e dois tipos de embalagens. 


\section{ACTA \\ AMAZONICA}

CONSERVAÇÃO E VIGOR DE SEMENTES

DE PAU-DE-BALSA (OCHROMA PYRAMIDALE) nas condições de câmaras úmida e seca, mostrando assim a importância das embalagens nessas alterações. Toledo \& Marcos Filho (1977) afirmaram que a utilização de embalagens adequadas permitem a conservação da qualidade das sementes, propiciando ou não, trocas de vapor d'água com o ar atmosférico. Neste sentido, Leão (1984) armazenou sementes de morototó (Didymopanax morototoni (Aublet.) Decne (espécie com características ortodoxa) em vários ambientes e tipos de embalagens e constatou, após o período de onze meses, que as sementes se conservaram melhor em câmara seca $\left(12^{\circ} \mathrm{C}\right.$ e $30 \%$ de UR) em embalagens de saco de papel e perderam, totalmente, o poder germinativo em ambiente natural, tanto nas embalagens permeáveis como semi-permeáveis.

Nas condições testadas (Figura 3) observou-se que o índice de velocidade de germinação decresceu, sugerindo perda do vigor. Carvalho \& Nakagawa (1983) mencionaram que o envelhecimento das sementes no decorrer do armazenamento é causado por mudanças fisiológicas e bioquímicas que normalmente ocorrem a partir da maturidade fisiológica. Neste sentido Pinto et al. (1986), usando o índice de velocidade de germinação, verificaram que as sementes de ipê-rosa (Tabebuia avellanedae Lor), espécie do grupo das ortodoxas (Cunha et al., 1992), diminuíram o vigor aos 15 e 30 dias após a colheita.

Independente de acréscimo ou não nos teores de água nas sementes (Figuras 2 e 3), houve redução do vigor. Garcia (2003) concluiu que Podocarpus lambertii Klotz tem comportamento de semente ortodoxa e após 135 dias de armazenamento, sofrem perdas acentuadas de viabilidade e vigor.

\section{CONCLUSÕES}

Concluiu-se que Ochroma pyramidale é ortodoxa e, acondicionando-se suas sementes em saco de papel, podese armazená-las em câmara úmida ou seca sem perda de sua viabilidade por um período de 400 dias, embora com diminuição do vigor em todas as condições testadas.

\section{AGRADECIMENTOS}

À Pesquisadora Vania Palmeira Varela, do Instituto Nacional de Pesquisas da Amazônia, pela revisão do trabalho.

\section{BIBLIOGRAFIA CITADA}

Bewley, J.D.; Black, M. 1985. Seeds: Physiology of development and germination. Plenum Press, New York. 367 p.

Brasil. 1992. Regras para análise de sementes. Secretaria Nacional de Defesa Agropecuária, Ministério da Agricultura, Brasília, 365 p.

Carvalho, N.M.; Goes, M.; Aguiar, I.B.; Fernandes, P.D. 1976. Armazenamento de sementes de ipê-amarelo (Tabebuia chrysotricha). Científica, 4(3):315-319.

Carvalho, N.M.; Nakagawa, J. 1983. Sementes: ciência, tecnologia e produção. 2 ed. Fundação Cargil, Campinas, 429 p.
Cunha, R. da; Salomão, A.N.; Eira, M.T.S.; Mello, C.M.C. de; Tanaka, D.M. 1992. Métodos para conservação a longo prazo de sementes de Tabebuia Spp - Bignoniaceae. In: $2^{\circ}$ Congresso Nacional sobre Essências Nativas. Anais...CENARGEN/EMBRAPA, Brasília. p.675-78.

Eira, M.T.S.; Salomão, A.N.; Cunha, R. da; Mello, C.M.C. de; Tanaka, D.M. 1992. Conservação de sementes de Copaifera langsdorffii Desf. Leguminosae. In: $2^{\circ}$ Congresso Nacional sobre Essências Nativas. Anais...CENARGEN/EMBRAPA, Brasília. p.523-26.

Figliolia, M.B. 1988. Conservação de sementes de essências florestais. Boletim Técnico do Instituto Florestal, 42:1-18.

Garcia, L.C. 2003. Aspectos morfo-anatômicos e tolerância à dessecação de sementes de Podocarpus lambertii Klotz e Podocarpus sellowii Klotz. (Podocarpaceae). Tese UFPR, Curitiba, 208 p.

Jones, L. 1967. Effects of storage at various moisture and temperatures on seed germination of silk oak, australian pine, and Eucalyptus spp.. U.S. Forest Service Research Note SE-83 USDA Southeastern Forest Experiment Station Macon, 4p.

Lamprecht, H. 1990. Silvicultura nos trópicos: ecossistemas florestais e respectivas espécies arbóreas - possibilidades e métodos de aproveitamento sustentado. Technische SuzammenarbeitVerlagsgesellschaft-Gesellschaft, Rossdorf, $343 \mathrm{p}$.

Leão, N.V.M. 1984. Conservação de sementes de morototó (Didymopanax morototoni (Aublet). Decne. Boletim de Pesquisa, 64, EMBRAPA-CPATU, Belém. 16 p.

Lorenzi, H. 1992. Árvores brasileiras: manual de identificação e cultivo de plantas arbóreas nativas do Brasil. Editora Plantarum, Nova Odessa, 351p.

Loureiro, A.A.; Silva, M.F. da; Alencar, J. da C. 1979. Essências madeireiras da Amazônia. INPA, Manaus, v. 2

Netto, D.A.M. 1994. Germinação de sementes de Pau-de-balsa (Ochroma pyramidale Cav. ex Lam.) Urban., Bombacaceae). Revista Brasileira de Sementes, 16(2): 159-162.

Pinto, M.M.; Sader, R.; Barbosa, J.M. 1986. Influência do tempo de secagem e do armazenamento sobre a viabilidade de sementes de ipê-rosa. Revista Brasileira de Sementes, 8(1): 37-47.

Roberts, E.H. 1973. Predicting the storage life of seeds. Seed Sci. E Technol., 1:499-514.

Toledo, F.F.; Marcos Filho, J. 1977. Manual de sementes: tecnologia da produção. Agronômica Ceres, São Paulo, 224p.

Varela, V.P.; Barbosa, A.P. 1986/87. Conservação de sementes de cedrorana (Cedrelinga catenaeformis Ducke) Leguminosae. Acta Amazonica, 16/17 (no. Único): 549-555.

Varela, V.P.; Ferraz, I.D.K. 1991. Germinação de sementes de Pau de balsa. Pesquisa Agropecuária Brasileira, 26(10):1685-1689.

Villiers, T.A. 1978. Seed moisture and storage. Seed Sci. \& Technol., 6:993-6.

Zanon, A.; Carpanezzi, A.A. 1993. Armazenamento de sementes de Grevillea robusta (Cunn. ex R. Br.). In: $1^{\circ}$ Congresso Florestal Panamericano; $7^{\circ}$ Congresso Florestal Brasileiro. Anais... Sociedade Brasileira de Silvicultura, Curitiba. p.265-267.

RECEBIDO EM 15/05/2002

ACEITO EM 26/02/2004 